\title{
miR-335 orchestrates cell proliferation, migration and differentiation in human mesenchymal stem cells
}

\author{
M Tomé ${ }^{1}$, P López-Romero², C Albo ${ }^{1}$, JC Sepúlveda ${ }^{1}$, B Fernández-Gutiérrez ${ }^{3}$, A Dopazo ${ }^{2}$, A Bernad ${ }^{\star 1,4}$ and MA González ${ }^{\star, 1,4}$
}

In spite of the extensive potential of human mesenchymal stem cells (hMSCs) in cell therapy, little is known about the molecular mechanisms that regulate their therapeutic properties. We aimed to identify microRNAs (miRNAs) involved in controlling the transition between the resting and reparative phenotypes of hMSCs, hypothesizing that these miRNAs must be present in the undifferentiated cells and downregulated to allow initiation of distinct activation/differentiation programs. Differential miRNA expression analyses revealed that miR-335 is significantly downregulated upon hMSC differentiation. In addition, hMSCs derived from a variety of tissues express miR-335 at a higher level than human skin fibroblasts, and overexpression of miR-335 in hMSCs inhibited their proliferation and migration, as well as their osteogenic and adipogenic potential. Expression of miR-335 in hMSCs was upregulated by the canonical Wnt signaling pathway, a positive regulator of MSC self-renewal, and downregulated by interferon- $\gamma$ (IFN- $\gamma$ ), a pro-inflammatory cytokine that has an important role in activating the immunomodulatory properties of hMSCs. Differential gene expression analyses, in combination with computational searches, defined a cluster of 62 putative target genes for miR-335 in hMSCs. Western blot and $3^{\prime}$ UTR reporter assays confirmed RUNX2 as a direct target of miR-335 in hMSCs. These results strongly suggest that miR-335 downregulation is critical for the acquisition of reparative MSC phenotypes. Cell Death and Differentiation (2011) 18, 985-995; doi:10.1038/cdd.2010.167; published online 17 December 2010

Mesenchymal stem cells (MSCs) are multipotent mesodermderived somatic stem cell (SSC) precursors of non-hematopoietic connective tissues that are present in the stroma of virtually all mammalian organs, especially bone marrow and subcutaneous fat (reviewed in Bernardo et al. ${ }^{1}$ ). Upon activation by tissue damage, MSCs contribute to tissue-repair processes through a multitude of activities, including cell proliferation, differentiation and migration, and the regulation of angiogenesis and immune responses. There is growing evidence, in both animal and clinical models, that administration of ex vivo-expanded human MSCs (hMSCs) has potential to ameliorate many degenerative disorders; however, the specific molecular mechanisms underlying this therapeutic potential remain mostly unknown.

MicroRNAs (miRNAs) are an extensive family of small (18-24 nucleotide), single-stranded non-coding RNAs, which regulate gene expression in eukaryotic cells by controlling the translation (usually by repression), stability and localization of specific mRNA targets. Computational predictions of miRNA targets indicate that each miRNA regulates hundreds of mRNAs, and that approximately one third of all mammalian protein-coding genes are regulated by miRNAs. ${ }^{2}$ Functional studies show that miRNAs participate in virtually each cellular process investigated, and that alterations in their expression levels might underlie human diseases, including cardiovascular disease and cancer. There are also data indicating that mammalian miRNAs can be imported into the nucleus ${ }^{3}$ or even secreted from cells within small exocytic particles, ${ }^{4}$ suggesting the existence of currently unknown functions for this class of molecules.

Experimental evidence shows that miRNAs are critical regulators of stem cell biology. In mouse embryonic stem (ES) cells, knockout of Dicer or DGCR8, two key protein factors involved in miRNA biogenesis, impairs cell growth, with cells accumulating in $\mathrm{G} 1$, and severely reduces differentiation capacity. ${ }^{5,6}$ Additionally, expression profiling demonstrates that ES cells express a unique repertoire of miRNAs compared with differentiated cell types. ${ }^{7}$ Molecular functions of ES cell-specific miRNAs have begun to be elucidated, and the results confirm their critical involvement in the regulation of ES cell pluripotency and self-renewal. miRNAs also have an important role in controlling ES cell differentiation and commitment. $^{8}$

To date, relatively few studies have examined miRNA function in MSCs. Gene expression microarray profiling has identified several miRNAs that are regulated during differentiation of MSCs into different cell lineages. Some of these miRNAs have been identified as regulators of osteogenic differentiation, including miR-125b, ${ }^{9}$ miR-26a, ${ }^{10}$ miR-196a, ${ }^{11}$ miR-204/211 ${ }^{12}$ and miRs-148b, -27a and $-489 .{ }^{13}$ Also, miR335 has been recently identified as the most upregulated miRNA in bone marrow-derived hMSCs in comparison with

\footnotetext{
${ }^{1}$ Department of Regenerative Cardiology, Centro Nacional de Investigaciones Cardiovasculares Carlos III (CNIC), Madrid, Spain; ${ }^{2}$ Genomics Unit, Centro Nacional de Investigaciones Cardiovasculares Carlos III (CNIC), Madrid, Spain and ${ }^{3}$ Rheumatology Service, Hospital Clínico San Carlos, Madrid, Spain

*Corresponding authors: A Bernad or MA González, Department of Regenerative Cardiology, Centro Nacional de Investigaciones Cardiovasculares Carlos III, Melchor Fernández Almagro, 3, 28029 Madrid, Spain. Tel: + 91453 1234; Fax: + 914531240 (AB); Tel: + 91453 1200; Fax: + 914531265 (MAG);

E-mails: abernad@cnic.es or magonzalez@cnic.es

${ }^{4}$ These authors share senior authorship.

Keywords: microRNA; mesenchymal stem cell; cell proliferation; cell migration; cell differentiation; osteogenesis

Abbreviations: hMSC, human mesenchymal stem cells; fdr, false discovery rate

Received 19.5.10; revised 19.10.10; accepted 10.11.10; Edited by JP Medema; published online 17.12.10
} 
skin fibroblasts, ${ }^{14}$ which are otherwise phenotypically similar to hMSCs. However, the specific targets of most of these miRNAs remain to be determined, and the possible role of miRNAs in other therapeutically relevant MSC activities, such as in cell migration and proliferation, is unknown.

Here, we sought to identify miRNAs that may regulate the activation of the reparative phenotype of hMSCs, as well as some of their target genes.

\section{Results}

miR-335 is downregulated upon hMSC differentiation. We hypothesized that key miRNA regulators of MSC activation/differentiation in tissue repair should be expressed in the undifferentiated state, and downregulated early upon exposure to a differentiation signal. To identify these putative miRNAs, we used Agilent microarrays to obtain differential miRNA expression profiles of undifferentiated bone marrow-derived hMSCs versus the same cells cultured in the presence of adipogenic or osteogenic media. We also profiled human skin fibroblasts, since the target miRNAs should be expressed at comparatively low levels in more developmentally restricted mesenchymal cell types. As we aimed to identify miRNAs potentially involved in the initial steps of hMSC activation/ differentiation, cells were exposed to differentiation media for a relatively short period (9 days), instead of the 21 days commonly used for in vitro MSC differentiation assays.

Signal processing is a critical step in the analysis of the results of miRNA microarray experiments. We used a normalization algorithm that incorporates quantile normalization between arrays ${ }^{15}$ to estimate a processed miRNA signal for the Agilent arrays. The quantile normalization, when applied to the background-corrected signal, showed significantly lower variability between replicates than the total gene signal normalized by the $75 \%$ percentile (Supplementary Figure S1).

The results showed no significant regulation (false discovery rate, $\mathrm{fdr}<15 \%$ ) of miRNAs previously described as regulators of osteogenic (miR-26a, miR-27a, miR-125b, miR-148b, miR-196a and miR-489) or adipogenic differentiation (miR-103, miR-107 and miR-143) under any of the conditions tested (Supplementary Figure S2A; Supplementary Table S1). Gene enrichment analysis of the predicted targets of miRNAs up- or downregulated in at least two conditions (see Materials and methods) showed a significant $(P<1 \mathrm{E}-06)$ enrichment for genes involved in angiogenesis or signaling by

Figure 1 miR-335 is downregulated in differentiated hMSCs and primary skin fibroblasts. (a) Total RNA was isolated from four bone marrow-derived MSC samples grown for 9 days in expansion medium or medium containing osteogenic or adipogenic supplements. In parallel, total RNA was also isolated from four dermal fibroblasts samples. The Venn diagrams show the number of miRNAs differentially expressed ( $\mathrm{fdr}<15 \%$ ) in each differentiated cell population, analyzed on Agilent V2 miRNA arrays. For fibroblasts, samples $(N=4)$ were analyzed individually, whereas for osteogenic and adipogenic differentiation, samples $(N=4)$ were pooled (two pools, two independent samples each) before microarray analysis. (b) Real-time RT-PCR validation of the microarray results for miR-335. Data are presented as mean \pm standard error. For RT-PCR experiments, $N \geq 3$

Wnt, integrins, PDGF, cadherin, endothelin and TGF- $\beta$ (Supplementary Figure S2B; Supplementary Table S1). miR-335 was the only miRNA significantly downregulated in all three 'differentiated' cell populations (Figure 1a). Fold-change (log2) values were as follows: fibroblast versus

a

\section{DIFFERENTIALLY EXPRESSED miRNAs} (vs. undifferentiated MSCs)
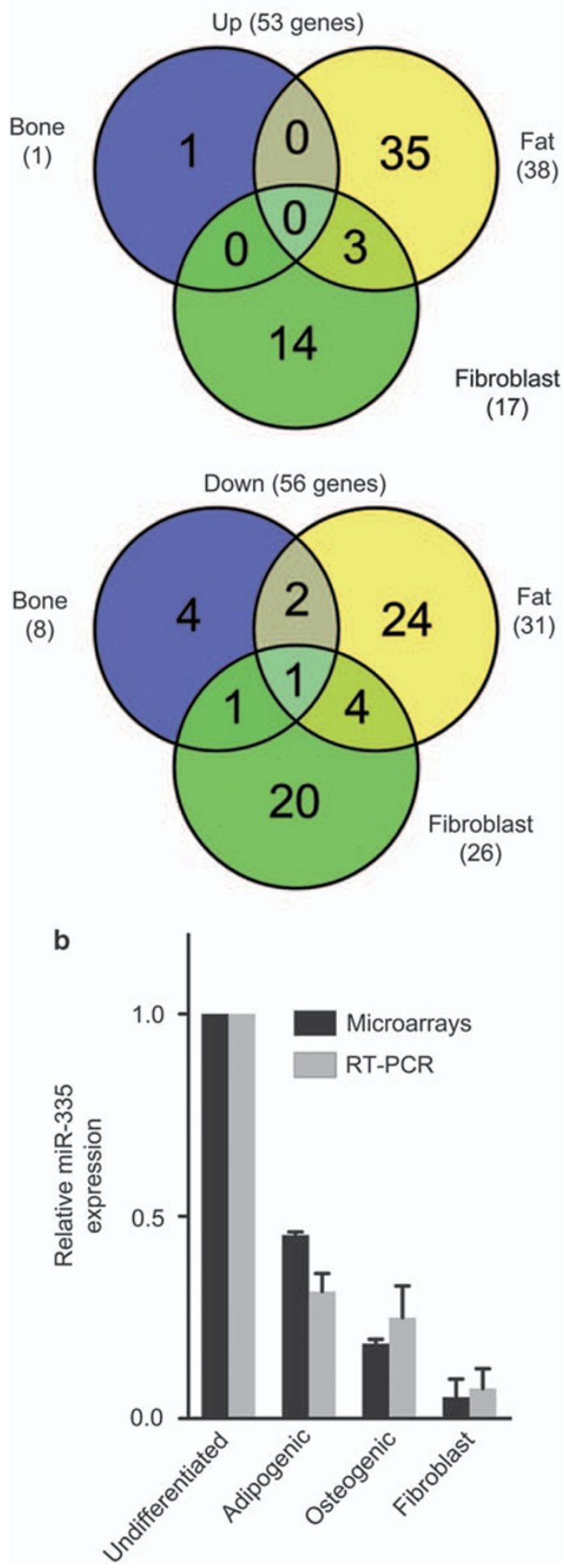
undifferentiated hMSCs, $M=-5.684$ ( $\mathrm{fdr}=0.008)$; osteogenic differentiation versus undifferentiated, $M=-2.434$ $(\mathrm{fdr}=0.029)$; adipogenic differentiation versus undifferentiated, $M=-1.141(\mathrm{fdr}=0.103)$. After validating the microarray results by real-time reverse transcriptase polymerase chain reaction (RT-PCR) (Figure 1b), we selected miR-335 for further characterization.

miR-335 levels were also significantly reduced in human osteoblasts (Saos-2 cell line) after differentiation (Supplementary Figure S4)

hMSCs from different tissues express higher levels than fibroblasts of miR-335 and its host gene MEST. To determine whether relatively high expression of miR-335 is specific to bone marrow-derived hMSCs or is a common characteristic of hMSCs, we analyzed miR-335 expression levels in hMSC populations obtained from bone marrow, subcutaneous adipose tissue and articular cartilage (Figure 2b). All hMSC isolates were tested at passage 5-7 at the same cell density $\left(8000\right.$ cells $\left./ \mathrm{cm}^{2}\right)$, and were assayed for their differentiation potential to osteogenic, adipogenic and chondrogenic lineages in the presence of specific differentiation factors (data not shown). All three populations express significantly higher levels of miR-335 than dermal fibroblasts, and miR-335 expression levels were significantly higher in hMSCs isolated from bone marrow or articular cartilage than in hMSCs derived from adipose tissue.

miR-335 is encoded by the second intron of the MEST (mesoderm-specific transcript homolog) gene (Figure 2a). ${ }^{16}$ MEST expression, determined by real-time RT-PCR, correlated with the levels of mature miR-335 (Figure 2b; Spearman's $r=0.5769, P=0.0008)$, suggesting that the different hMSC isolates co-express mature miR-335 with its host gene and not through an MEST-independent mechanism (such as a specific promoter or post-transcriptional regulation).

MEST expression levels also correlated with the levels of miR-335 under all other conditions tested in this study (Supplementary Figure S5).

miR-335 impairs hMSC proliferation, migration and differentiation. We next analyzed the effect of miR-335 overexpression in bone marrow-derived hMSCs. hMSCs were transduced with the lentiviral vector pLV-EmGFP. MIR335, which encodes the genomic sequence spanning miR-335, or with a control vector (pLV-EmGFP-Mock). Transduced cells were purified to $>95 \%$ homogeneity (gfppositive cells) by fluorescence-activated cell sorting (FACS). To avoid non-specific effects due to lentiviral gene silencing or to a high proviral copy number per cell, a multiplicity of infection (MOI) of 5 was used, and only cells with mediumlevel gfp expression were selected (Supplementary Figure S3A). Real-time RT-PCR demonstrated an 3-fold increase in miR-335 expression in pLV-EmGFP-MIR335-transduced cells compared with controls (Supplementary Figure S3B).

When cultured over several passages, miR-335-overexpressing hMSCs showed a significant reduction in their proliferative activity compared with control cells (Figure 3a). However, miR-335 overexpression did not cause significant

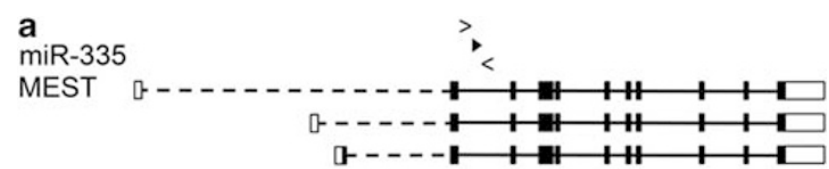

b

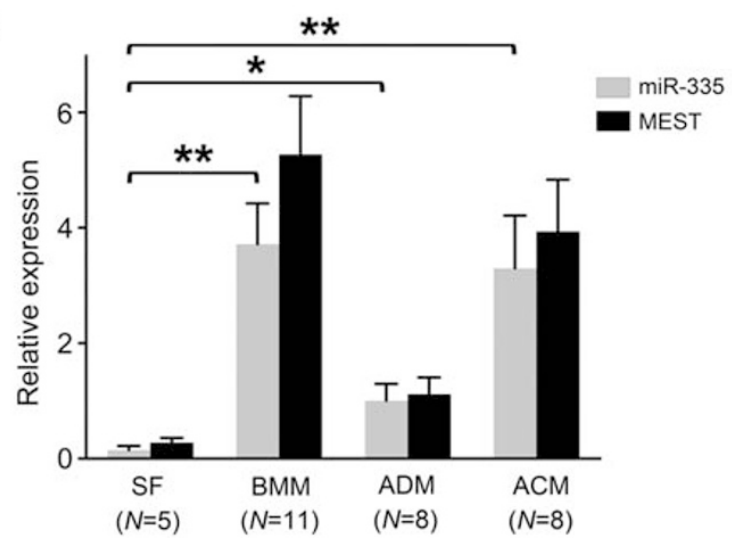

Figure 2 The expression levels of miR-335 in human mesenchymal cells correlate with those of its host coding-gene MEST. (a) Simplified map $\left(5^{\prime} \rightarrow 3^{\prime}\right)$ of the human MEST locus (chromosome 7: 130126 046-130 146 133) showing the three MEST transcript variants (lower line/box diagrams) and the position of the genomic sequence encoding miR-335 (MIRN335, upper black arrowhead). Boxes represent exons. Black boxes/solid lines indicate coding regions, and white boxes/ dashed lines indicate untranslated regions. Arrowheads mark the position of the primers used to amplify the miR-335-encoding sequence for cloning into the lentiviral expression vector. (b) Relative expression levels of miR-335 (endogenous control RNU-48) and MEST (endogenous control GAPDH) were measured by realtime RT-PCR in human skin fibroblasts (SF) and in hMSCs isolated from bone marrow (BMM), adipose tissue (ADM) or articular cartilage (ACM). Data are means \pm standard error. ${ }^{*} P \leq 0.05 ;{ }^{\star *} P \leq 0.005$ (Mann-Whitney U-test). The number of independent samples tested $(M)$ is indicated on the $x$ axis

alterations to cell cycle kinetics (not shown) or the rate of apoptosis (Figure $3 \mathrm{~b}$ ).

hMSCs overexpressing miR-335 also showed an impaired migratory response to stimulation with fetal bovine serum (Figure 3c). Consistently, wild-type hMSCs transfected with an miR-335 inhibitor (Anti-miR-335, Ambion, Austin, TX, USA) showed increased migratory activity compared with cells transfected with a negative control Anti-miR oligonucleotide (Figure 3c; Supplementary Figure S3C). miR-335-overexpressing hMSCs also showed impaired migratory activity in an in vitro wound-healing assay compared with control cells (see Supplementary information videos). These results demonstrate that $\mathrm{miR}-335$ is a negative regulator of $\mathrm{hMSC}$ migration.

The effect of miR-335 expression on hMSC differentiation capacity was monitored by comparing the in vitro differentiation responses of control and miR-335-transduced hMSCs to exposure to adipogenic or osteogenic stimuli for 3 weeks. Both adipogenic and osteogenic differentiation were significantly reduced by miR-335 overexpression. In particular, in vitro osteogenesis was almost completely abolished (Figure 3d), indicating a role for miR-335 in the regulation of hMSC differentiation programs. Analysis of expression of the differentiation markers osteopontin (osteogenic differentiation) and PPAR $\gamma$ (adipogenic differentiation) confirmed the inhibitory effect of miR-335 in both processes (Figure 3e). 

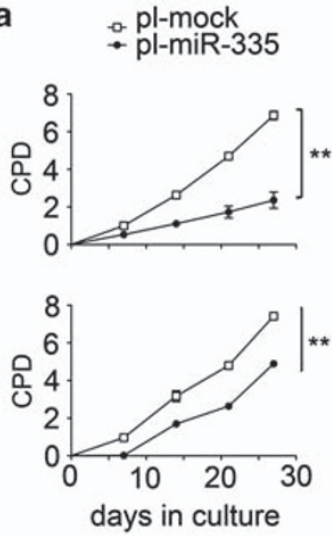

d

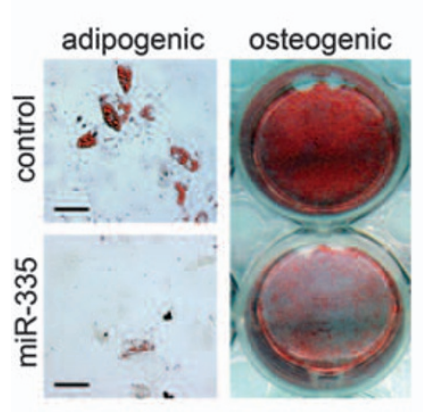

b

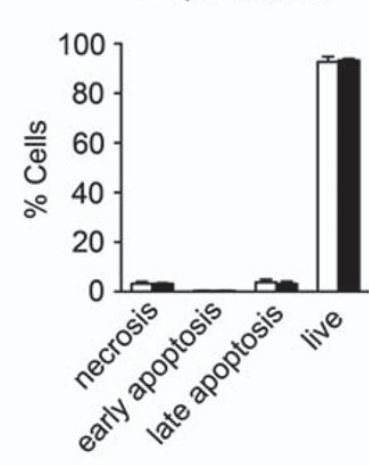

e c

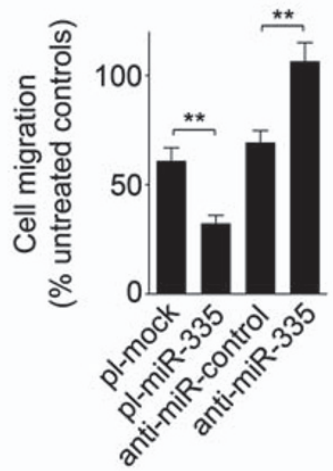

pl-mock

pl-miR-335
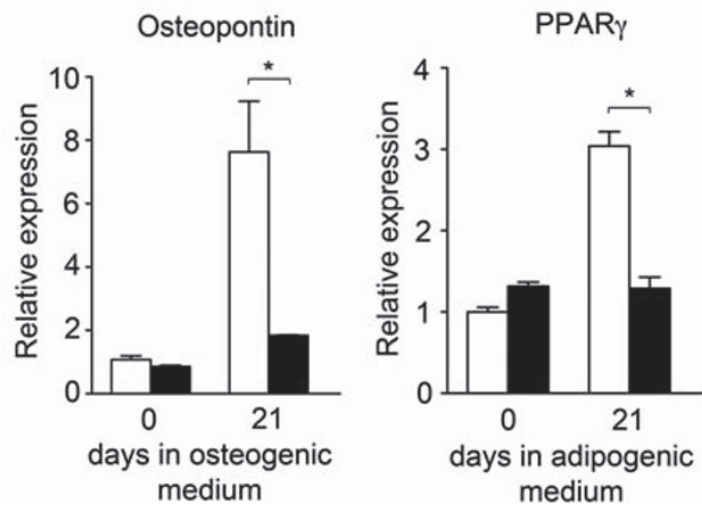

Figure 3 Exogenous miR-335 overexpression impairs hMSC proliferation, migration and differentiation. Bone marrow-derived hMSCs were transduced with the lentiviral vectors pLV-EmGFP-MIR335 or pLV-EmGFP-mock (encoding a negative control shRNA) and transduced ( $\mathrm{gfp}+$ ) cells were purified by FACS. The purified cells (pl-miR-335 and pl-mock, respectively) were used in gain-of-function studies. (a) Cumulative population doublings (CPDs) over several culture passages of pl-miR-335 (solid circles) and pl-mock (open squares) cells from two donors. $P$-values were calculated for CPD at the end of the assay. $N=3$. (b) Percent of living, necrotic and apoptotic cells determined by the Annexin V binding assay. Annexin V binding was analyzed by cell cytometry using Cell Quest software (BD Biosciences). $N=6$. (c) hMSCs (10 ${ }^{4}$ ) transduced with the indicated lentiviral vector or transfected with the indicated miRNA inhibitor were used in transwell migration assays. $N=3$. (d) hMSCs transduced with pLV-EmGFP-MIRN335 or pLV-EmGFP-mock (control) were cultured for 3 weeks in medium containing adipogenic or osteogenic factors, followed by staining with Oil Red O or Alizarin Red S, respectively. Representative images are shown. $N \geq 3$. Scale bars, $50 \mu \mathrm{m}$. (e) Relative expression levels of marker genes osteopontin and PPAR (endogenous control GAPDH) were measured by real-time RT-PCR in hMSC cultured in osteogenic or adipogenic medium, respectively. $N=3$. For all panels, data are means \pm standard error. ${ }^{*} P \leq 0.05 ;{ }^{* *} P \leq 0.005$ (Mann-Whitney U-test)

miR-335 expression levels are regulated by signals that control MSC migration and differentiation. The apparent regulatory role of miR-335 in hMSC suggested that it might be regulated by signals known to control MSC biology. We therefore tested if canonical Wnt signaling, a negative regulator of MSC differentiation, ${ }^{17}$ affected miR-335 expression levels. Bone marrow-derived hMSCs treated with $10 \mathrm{mM} \mathrm{LiCl}$ or Wnt3a-containing conditioned medium upregulated miR-335 expression (Figure 4a, left panel). Moreover, addition of Dkk1 $(100 \mathrm{ng} / \mathrm{ml})$, a specific inhibitor of canonical Wnt signaling, significantly decreased miR-335 expression in the presence of exogenous Wnt3a (Figure 4a, right panel). Upregulation of miR-335 expression by Wnt3a was also observed in adipose-derived hMSCs and in skin fibroblasts (Figure 4b), although in a different extension, suggesting that this effect is common to all mesenchymal cell types.

We next evaluated the effect on miR-335 expression of interferon- $\gamma(\mathrm{IFN}-\gamma)$ signaling, another key regulator of MSC activity. IFN- $\gamma$ has numerous actions on MSC, including the induction of immunorregulatory activity, cell migration and osteogenic differentiation. ${ }^{18,19}$ Treatment of bone marrow-derived hMSCs with human IFN- $\gamma$ for $48 \mathrm{~h}$ significantly decreased expression of miR-335 (Figure 4c) in a dose-dependent manner, consistent with the lowered miR-335 expression during cell migration and osteogenic differentiation.

To identify possible binding sites in the MEST locus for transcription factors involved in $\beta$-catenin or IFN $\gamma$ signaling pathways, we performed a multispecies (human, mouse and dog) sequence homology analysis for conserved binding sites for LEF/TCF (transcription factors involved in $\beta$-catenin signaling) and STAT1 (involved in IFN $\gamma$ signaling). MULAN analysis with a matrix similarity of 0.95 showed one possible LEF1 and one possible TCF4 site in the 5-kb region upstream of the MEST transcriptional start site (corresponding to the longest human splicing variant), both mapping at $-2675 \mathrm{~kb}$ (Supplementary Figure S6). A similar analysis, with a matrix 
similarity of 0.90 , identified three conserved potential STAT1binding sites at $-4440,-4384$ and $-4303 \mathrm{~kb}$ (Supplementary Figure S6).

Potential miR-335 targets in hMSCs are enriched in transcription regulators of cell movement and differentiation. In order to identify potential miR-335 targets, we used a two-step approach (Figure 5a). First, we employed three different miRNA target prediction programs, miRanda, ${ }^{20}$ TargetScan $^{21}$ and PicTar, ${ }^{22}$ to obtain a list of putative miR-335 targets. As these programs use different target scoring systems, we combined the three lists in a single non-redundant gene list (a total of 1838 genes, of which 1607 were mapped). Gene enrichment analysis using
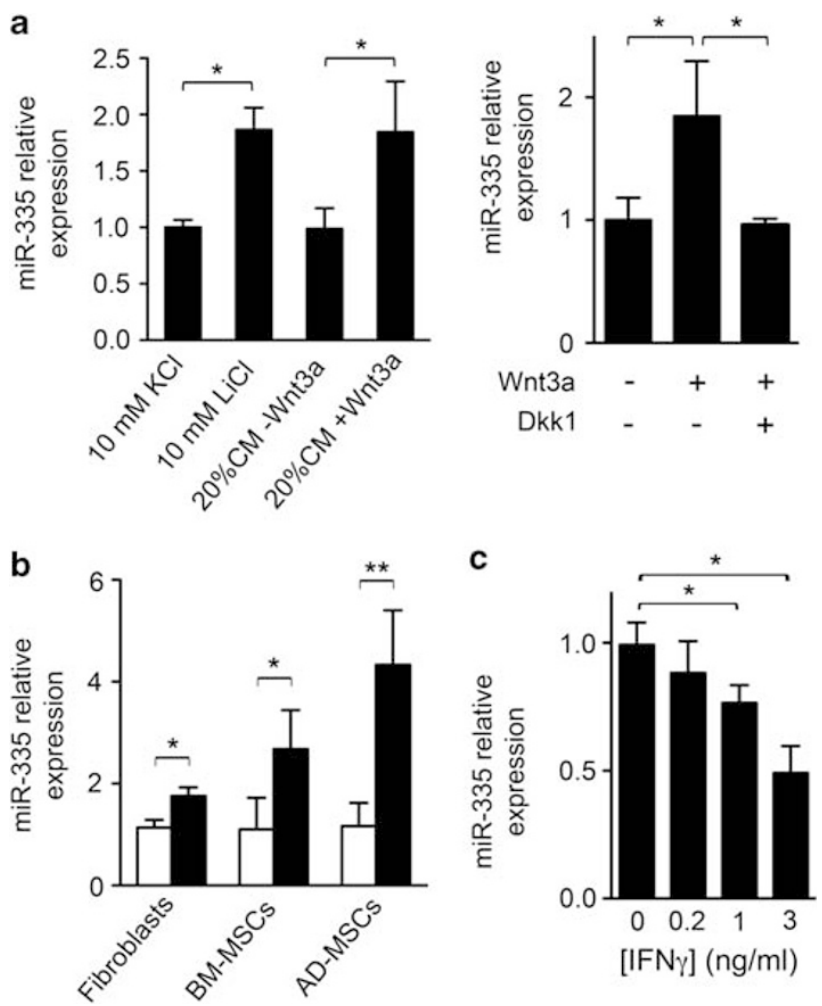

Figure 4 miR-335 expression is regulated by signals controlling hMSC proliferation, migration and differentiation. (a) Left panel, bone marrow-derived hMSCs $\left(8000 \mathrm{cells} / \mathrm{cm}^{2}\right)$ were incubated for $48 \mathrm{~h}$ in the presence of medium containing $10 \mathrm{mM} \mathrm{KCl}, 10 \mathrm{mM} \mathrm{LiCl}, 20 \%$ conditioned medium without Wnt3a (CM-Wnt3a), or 20\% Wnt3a-containing conditioned medium (CM + Wnt3a), and miR-335 relative expression was quantified by real-time RT-PCR. Right panel, relative expression of miR-335 in $\mathrm{hMSC}$ cultured in 20\% CM-Wnt3a, 20\% $\mathrm{CM}+$ Wnt3a or $20 \% \mathrm{CM}+$ Wnt3a containing $100 \mathrm{ng} / \mathrm{ml}$ of the Wnt inhibitor Dkk1. Relative expression levels are calculated as the fold change compared with the same cell type grown in standard culture conditions. (b) Human dermal fibroblasts (four different isolates), bone marrow-derived hMSCs (BM-MSC, two different isolates) and adipose-derived hMSC (AD-MSC, three different isolates) were incubated in 20\% CM-Wnt3a (white bars), or 20\% CM + Wnt3a (black bars), and miR-335 relative expression was quantified by real-time RT-PCR. Relative expression levels are calculated as the fold change compared with the same cell type grown in standard culture conditions. (c) Bone marrow-derived hMSCs were incubated with medium containing different concentrations of human IFN $\gamma$ for $48 \mathrm{~h}$, and miR-335 expression was determined by real-time RT-PCR. For all panels, data are means \pm standard error. ${ }^{*} P \leq 0.05 ;{ }^{*} P \leq 0.005$ (Mann-Whitney U-test). $N \geq 3$ the PANTHER database revealed significant enrichment $(P<0.001)$ for molecular functions related to transcriptional and post-transcriptional gene regulation, and for biological processes $(P<1 \mathrm{E}-06)$ also related to regulatory activities, including mRNA transcription, protein modification and signal transduction (Supplementary Figure S7).

Second, we performed a microarray gene expression analysis (Agilent Whole Human Genome Microarray Kit) on hMSCs transduced with pLV-EmGFP-MIR335 or pLVEmGFP-mock. We focused on downregulated genes since mRNA expression levels tend to correlate negatively with the expression levels of their specific miRNAs. ${ }^{23}$ Using this approach, we identified 489 genes with decreased expression in miR-335-transduced cells that are thus candidate direct or indirect targets of this miRNA in hMSCs. Of these genes, 62 were also contained in the previously obtained list of predicted miR-335 targets (Supplementary Table S2), and were therefore classed as probable direct targets. This set of 62 genes was significantly enriched $(P<0.05)$ for transcription factors (21\%) and membrane-bound signaling molecules $(6.5 \%)$. A detailed analysis with the Ingenuity Pathways Analysis software (IPA, Ingenuity Systems, Redwood City, CA, USA, http://www.ingenuity.com) showed a predominant enrichment for functions involved in cell development, cell movement, gene expression and the cell cycle (Benjamini-Hochberg multiple test-corrected $P$-value $=1.37 \mathrm{E} 02-8.82 \mathrm{E}-02)$. Other significantly enriched biological functions included cell signaling, cell growth and proliferation, cell morphology, cell

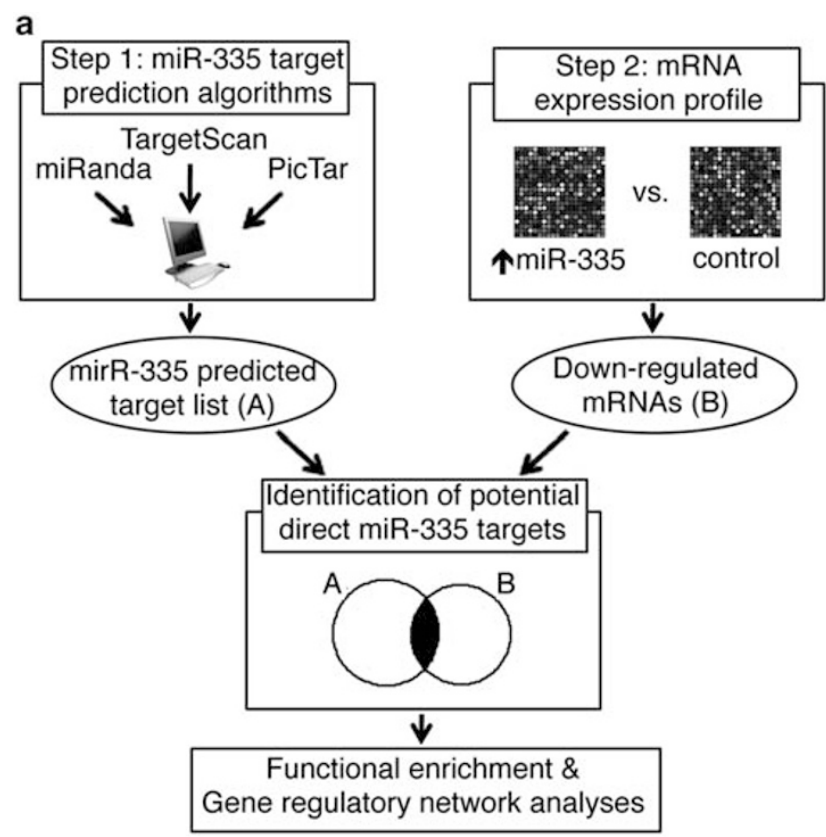

Figure 5 The set of potential miR-335 targets in hMSCs is enriched for cell movement and transcriptional regulatory functions. (a) Strategy used to identify potential mRNA targets of miR-335 in hMSCs. Sixty-two genes were identified by both target prediction algorithms and expression profiling (represented by the overlap in the Venn diagram). (b) Ingenuity Pathways Analysis was performed on the 20 cell movement-related genes and the 17 gene expression-related genes identified among the 62 potential miR-335 targets. The panels show the most significant networks found, including 11 (of 20, score 27 ) and 15 (of 17, score 42) genes, respectively (shaded) 
b

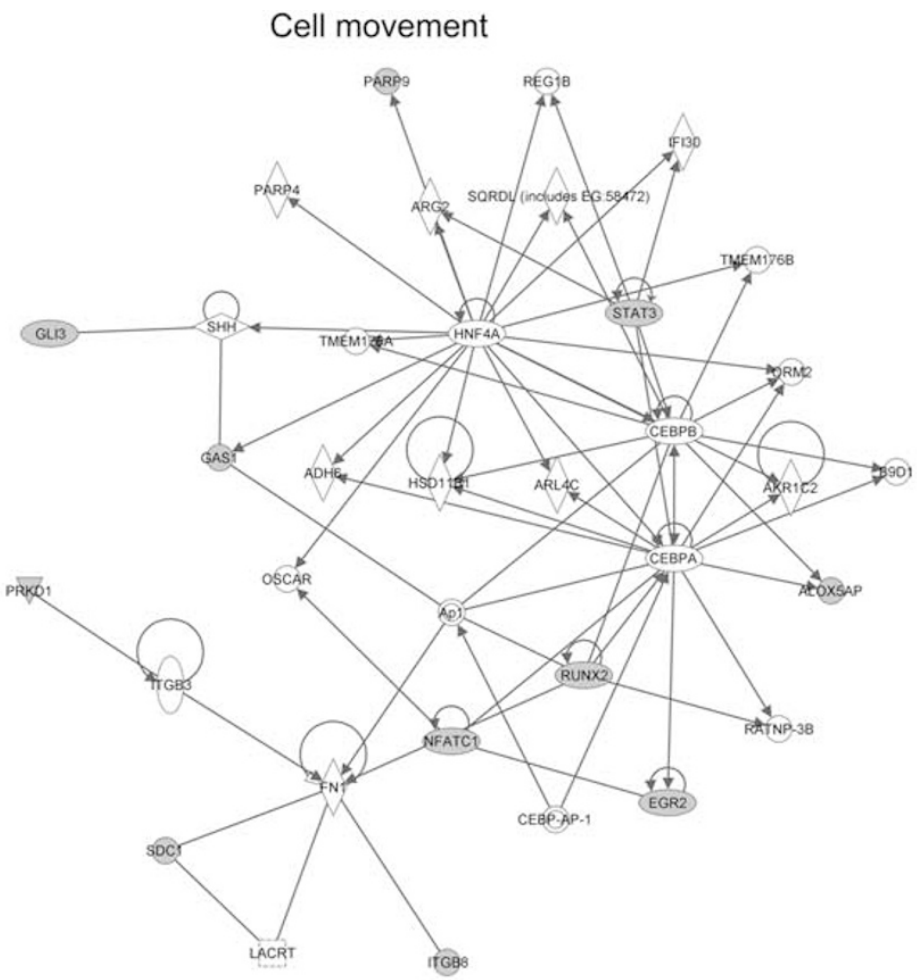

Gene expression

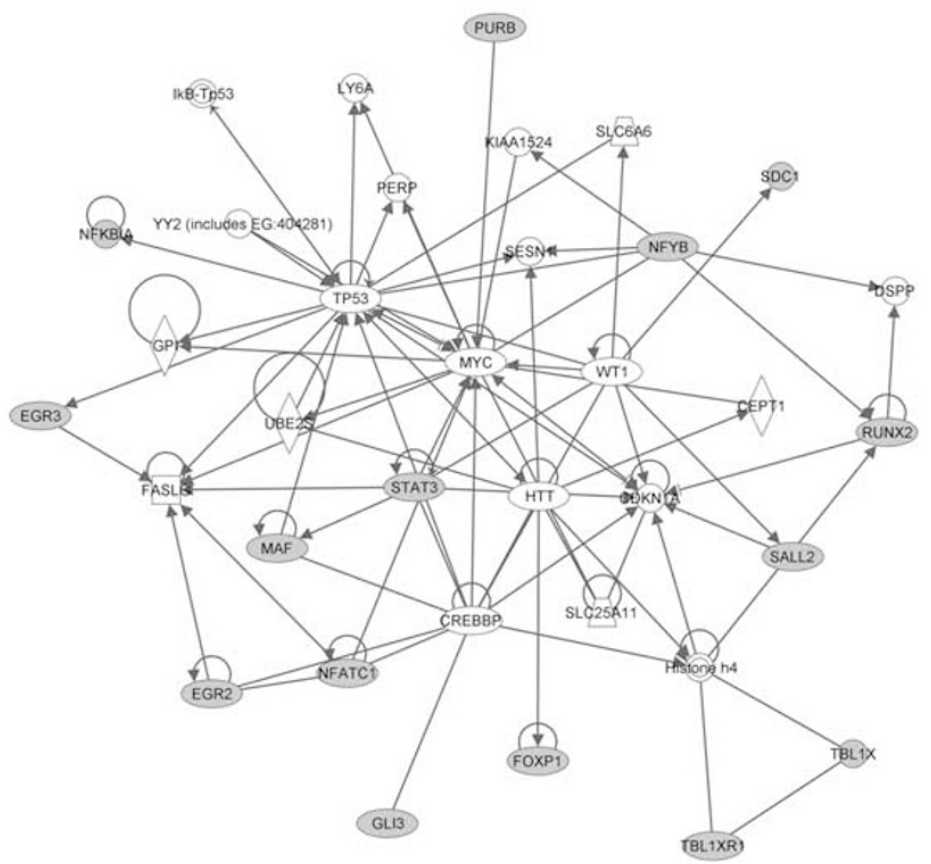

0 Transmembrane Receptor

$\square$ Transporter

O Other

\section{$\nabla$ Kinase}

(C) Group or Complex

G-protein Coupled Receptor

Figure 5 Continued 
commitment and cell death (Table 1). Using IPA, the two more representative gene regulatory networks were constructed, respectively, containing 11 of the 20 potential miR-335 target genes involved in cellular movement (score 27) and 15 of the 17 genes involved in gene expression (score 42) (Figure 5b).

One of the predicted targets of miR-335 is RUNX2, a key transcription factor involved in osteogenesis. Although miRNAs can bind to coding regions and even to 5'regulatory regions, a single miR-335 binding site is predicted by the miRanda algorithm at nucleotides 3545-3567 in all the known

Table 1 Most significantly enriched molecular and cellular functions found using the IPA software in the list of 62 genes identified as potential miR-335 targets in hMSCs (B-H $P$-value: Benjamini-Hochberg multiple test-corrected $P$-value)

\begin{tabular}{lcc}
\hline Relevant functions & B-H $\boldsymbol{P}$-value & $\begin{array}{c}\text { No. of } \\
\text { Molecules }\end{array}$ \\
\hline Cellular development & $1.37 \mathrm{E}-02-8.82 \mathrm{E}-02$ & 21 \\
Cellular movement & $1.37 \mathrm{E}-02-8.82 \mathrm{E}-02$ & 20 \\
Gene expression & $1.37 \mathrm{E}-02-8.82 \mathrm{E}-02$ & 17 \\
Cell cycle & $1.37 \mathrm{E}-02-8.82 \mathrm{E}-02$ & 3 \\
Cell signaling & $1.76 \mathrm{E}-02-6.70 \mathrm{E}-02$ & 4 \\
Cellular growth and proliferation & $2.47 \mathrm{E}-02-8.82 \mathrm{E}-02$ & 19 \\
Cell morphology & $2.58 \mathrm{E}-02-8.52 \mathrm{E}-02$ & 11 \\
Cellular compromise & $2.58 \mathrm{E}-02-5.84 \mathrm{E}-02$ & 6 \\
Cell death & $2.58 \mathrm{E}-02-8.82 \mathrm{E}-02$ & 18 \\
\hline
\end{tabular}

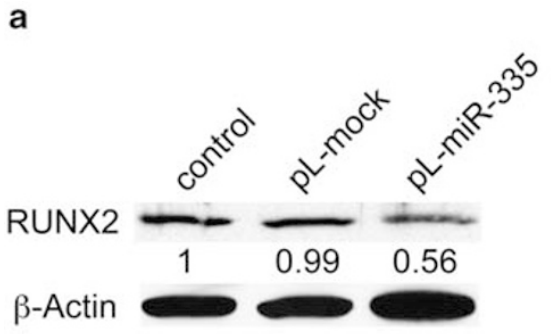

C

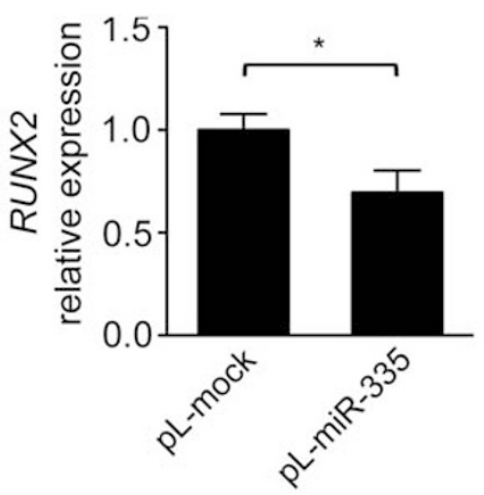

RUNX2 transcript variants (GenGank Accession Numbers NM_001024630, NM_001015051, NM_004348), corresponding to the $3^{\prime} \cup T R$ region.

A western blot analysis of RUNX2 demonstrated that its protein levels are reduced in hMSCs by miR-335 exogenous overexpression (Figure 6a). To determine whether miR-335 directly modulates RUNX2 expression levels in hMSCs, we cloned the full-length RUNX2 3'UTR downstream of the Renilla luciferase gene as a reporter, and assayed its expression in hMSCs transfected with a synthetic precursor or a specific inhibitor of miR-335. UTR reporters corresponding to SOX4 and UBE2F genes were used as positive and negative controls, respectively, for the miR-335 inhibitory activity. ${ }^{24}$ Transfection of the miR-335 synthetic precursor significantly reduced the expression of UTR reporters for SOX4 and RUNX2, but not the expression of the negative control gene UBE2F (Figure 6b, upper panel). Transfection with the specific inhibitor of miR-335 significantly increased the expression levels of UTR reporters for SOX4 and RUNX2, but did not affect the levels of UBE2F (Figure 6b, bottom panel). These results indicate that miR-335 controls RUNX2 expression in hMSCs by direct binding to its $3^{\prime} U T R$.

Finally, we have quantified the relative expression levels of RUNX2 after osteogenic differentiation in hMSCs b
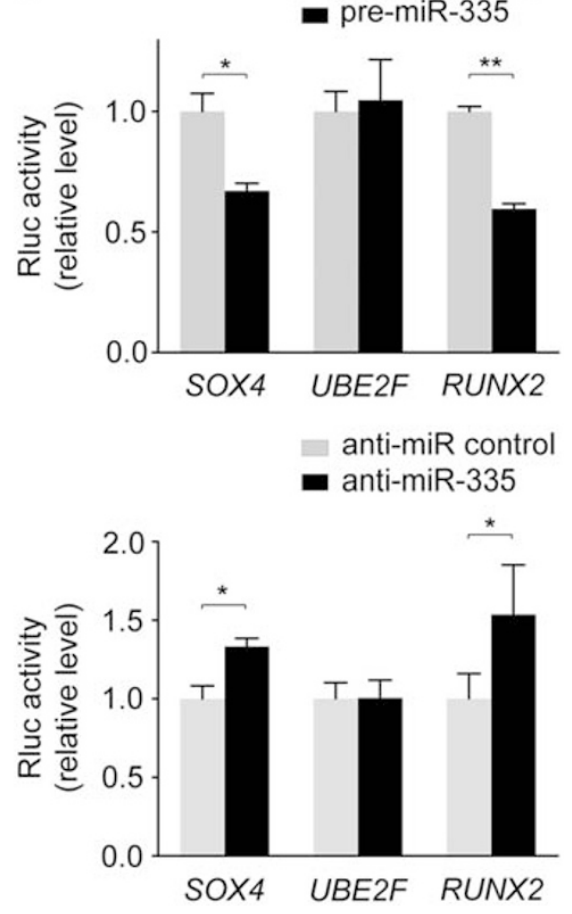

Figure 6 RUNX2 is a direct target of miR-335. (a) Western blot of total cell protein $(30 \mu \mathrm{g})$ from wild-type hMSCs and hMSCs transduced with a lentiviral vector encoding miR-335 (pL-miR-335) or a negative control shRNA (pL-mock). Numbers represent densitometry values of RUNX2 protein normalized to $\beta$-Actin standard. (b) UTR reporter assay of RUNX2. Reporter constructs consisting of the Renilla luciferase sequence fused to the $3^{\prime} U T R s$ of RUNX2, SOX4 (positive control) or UBE2F (negative control) were co-transfected with synthetic miRNA precursors or antagonists into hMSCs. Renilla luciferase (Rluc) activity was assayed $30 \mathrm{~h}$ after transfection, and the values were normalized to the activity of firefly luciferase encoded in the same vector. (Upper panel) Pre-miR-control (gray bars); pre-miR-335 (black bars). (Lower panel) Anti-miR-control (gray bars); anti-miR-335 (black bars). (c) Relative expression levels of RUNX2 (endogenous control GAPDH) were measured by real-time RT-PCR in hMSC transduced with a lentiviral vector encoding miR-335 (pL-miR-335) or a negative control shRNA (pL-mock), cultured in osteogenic medium for 15 days. Data are means \pm standard error. ${ }^{\star} P<0.05 ;{ }^{*} P<0.005$ (Mann-Whitney U-test); $N=3$ 
overexpressing miR-335. The results of these experiments (Figure 6c) showed a significant reduction of RUNX2 expression levels in the cells transduced with the lentiviral vector encoding miR-335, compared with those transduced with a control lentiviral vector, which is in good agreement with the rest of the data indicating that $R U N X 2$ is a target of miR-335 in hMSCs.

\section{Discussion}

Our results support a central role for miR-335 in the gene regulatory network that controls the tissue-repair activities of hMSCs. Expression of this miRNA is high in undifferentiated multipotent hMSCs compared with their differentiated cell progeny, and is regulated by major signaling pathways that control MSC biology, such as those controlled by Wnt3a and IFN $\gamma$. The set of predicted miR-335 targets is enriched in genes whose products are regulators of cellular movement and gene expression, including $R U N X 2$, involved in the control of osteogenic differentiation.

There is growing evidence that miRNAs have a critical role in the biology of all stem cell types, including ES cells, germline stem cells and SSCs. As SSCs are usually less well defined than embryonic or germline stem cells, it has been difficult to identify the specific roles of an miRNA in a particular SSC population. Most miRNAs described as regulators of SSC biology are inducers of cell differentiation/commitment or inhibitors of self-renewal and proliferation, while others seem to be involved in the self-renewal or maintenance of some SSC types. ${ }^{25}$

Our results demonstrate that miR-335 is downregulated in hMSC cultures undergoing adipogenic or osteogenic differentiation, and is also expressed at comparatively lower levels in skin fibroblasts, which are mesenchymal cells with a limited differentiation potential. Our data are in complete accordance with previous work identifying miR-335 as the most upregulated miRNA in bone marrow-derived hMSCs in comparison with fibroblasts. ${ }^{14}$

Until recently, the only known specific biological role for miR-335 is in human breast cancer, where it has been proposed as a metastasis suppressor. ${ }^{24}$ Expression of miR-335 is lost in the majority of primary breast tumors from patients who relapse, and this is associated with poor distal metastasis-free survival. ${ }^{24}$ These results are in good agreement with our findings demonstrating that miR-335 is a negative regulator of hMSC migration. miR-335 downregulation is also observed in drug-resistant ovarian cancer cells, ${ }^{26}$ cultured chondrocytes (versus cartilage tissue), ${ }^{27}$ ethanoltreated neural progenitors, ${ }^{28}$ multiple myeloma cells and tumors $^{29}$ and muscle regeneration. ${ }^{30}$ In contrast, miR-335 is highly expressed in obesity models ${ }^{31}$ and in fetal lung compared with adult tissue. $^{32}$ During the preparation of this manuscript, a communication describing the direct targeting of $R B 1$ by miR-335 has been published. ${ }^{33}$ In this study, the authors establish the important role of this miRNA in the induction of p53-dependent cell cycle arrest after DNA damage. These results are in accordance with our findings demonstrating that miR-335 is a negative regulator of hMSC proliferation, and, taken together with our results, suggest an important role of miR-335/RB1 activity in regulation/activation of hMSC tissue-repair activities.

miR-335 is encoded by the second intron of the maternally imprinted gene MEST (human chromosome 7q32). ${ }^{16}$ Our results demonstrate that both miR-335 and MEST are coordinately upregulated in hMSCs from three different tissues (bone marrow, subcutaneous fat and articular cartilage) in comparison with skin fibroblasts. The biological relevance of this finding remains to be determined, but our results suggest that miR-335 expression levels could be used to discriminate between hMSCs and fibroblasts, or even between different MSC populations with diverse differentiation potentials.

We found no significant regulation of miRNAs previously described as regulators of osteogenic differentiation (miR26a, miR-27a, miR-125b, miR-148b, miR-196a, miR-489 and miR-204/211) or adipogenic differentiation (miR-103, miR107 and miR-143) under any of the conditions tested. This apparent discrepancy with published data might be related to the fact that our microarray analyses were performed on hMSCs at early differentiation stages, unlike other studies that used terminally differentiated MSCs. Also, the method we used for signal processing (quantile normalization) ${ }^{15}$ probably contributed to an overall reduction in the variation of gene expression between samples.

The finding that miR-335 expression impairs the proliferative and migratory capacities of primary bone marrow-derived hMSCs and inhibits both adipogenic and osteogenic differentiation suggests that miR-335 is part of a common regulatory pathway for cell proliferation, migration and differentiation in MSCs. The existence of a partially overlapping regulatory circuitry for these biological processes has already been demonstrated in MSCs, ${ }^{17}$ as well as in other SSC lineages. ${ }^{34}$ The role of canonical Wnt signaling pathway (Wnt3a) as a positive regulator of miR-335 expression in hMSCs agrees with the evidence showing that Wnt3a inhibits osteogenic differentiation in MSCs. ${ }^{17}$ However, the observed reduction in proliferation capacity in hMSCs overexpressing miR-335 suggests that the reported proliferative effect of Wnt3a acts via miR-335-independent mechanisms. Also, it has been reported that Wnt3a induces ECM invasion in hMSCs, ${ }^{35}$ although it inhibits it in murine MSCs. ${ }^{36}$ Further studies are needed to determine the effects of Wnt3a in the migration capacity of hMSCs in different regulatory conditions, and if they are related to miR-335 upregulation.

In contrast with the effect of Wnt3a, IFN $\gamma$ decreased miR-335 expression in hMSCs. Considered together with the anti-migratory and differentiation effects of miR-335, this action might account, at least partially, for the previously described pro-migratory and pro-osteogenic activities of IFN $\gamma .{ }^{19}$ This cytokine has a key role in the therapeutic activity of MSCs, as it is involved in the activation of their immunomodulatory phenotype. ${ }^{18}$ IFN $\gamma$ signaling, both intercellular and autocrine, might thus regulate an unsuspected large number of genes in MSCs through the inhibition of miR-335 expression. At this time, we do not know the precise molecular mechanism by which IFN $\gamma$ downregulates miR-335 expression in MSC, but it might involve an indirect effect through its previously described inhibitory action on the canonical Wnt signaling pathway. ${ }^{37}$ 


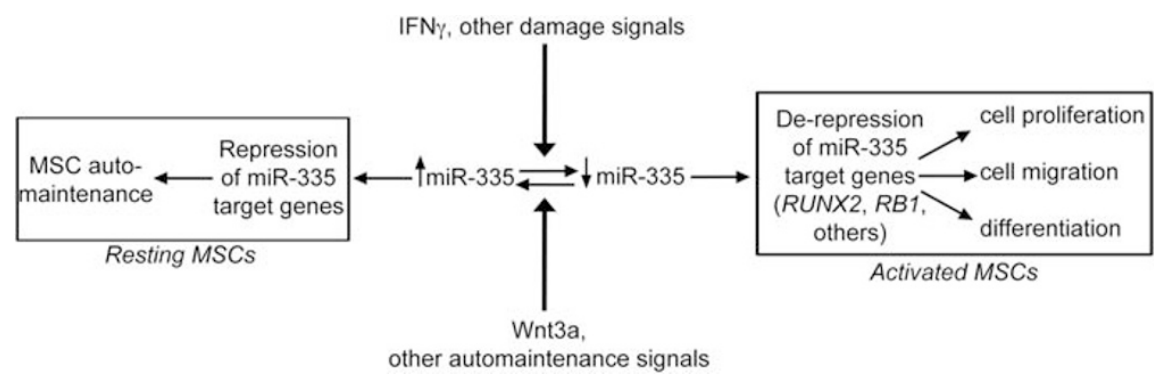

Figure 7 Working model for miR-335 control of MSC activation. In healthy tissues (homeostasis), physiological levels of Wnt3a, in co-ordination with other stimuli, keep miR-335 expression levels high in MSCs. Upon tissue damage or challenge, IFN $\gamma$, probably also in combination with other proinflammatory signals, induce miR-335 downregulation, which in turns causes the de-repression of its target genes, RUNX2 among them. This activates the MSC reparative phenotype, characterized by an increased proliferative, migratory and differentiation capacities

Comparative genomics is a powerful new tool for identifying and characterizing functional sequences. The presence in the $5^{\prime}$ upstream region of the MEST locus of highly conserved potential LEF1 and TCF4-binding sites (95\% similarity between human, mouse and dog) and potential STAT1binding sites is compatible with the regulation of the MEST/ miR-335 locus by both Wnt3a and IFN $\gamma$.

Consistent with our experimental results, the set of 62 potential direct gene targets of miR-335 is significantly enriched in genes related to cell movement and gene expression, pointing to a key regulatory role of miR-335 in MSC biology. In particular, we have experimentally validated RUNX2, a transcription factor essential for osteogenic differentiation, as a direct miR-335 target. Recently, miR-204 and miR-211 have been described as negative regulators of RUNX2. ${ }^{12}$ Taken together, these results demonstrate that osteogenic differentiation of mesenchymal precursors is regulated by multiple miRNAs through the control of RUNX2 expression levels.

To our knowledge, this is the first demonstration of the involvement of a specific miRNA in the coordinated regulation of MSC proliferation, migration and differentiation. Our findings are summarized in the model presented in Figure 7. miR-335 is downregulated in MSCs in response to tissue damage signals, such as IFN $\gamma$, which leads to de-repression of miR-335 target genes involved in MSC proliferation, migration and osteogenic differentiation. These results have implications for the understanding of the major molecular mechanisms controlling the therapeutic activity of hMSCs versus their maintenance in an undifferentiated state, and strongly suggest an important role of miR-335 in tissue homeostasis.

\section{Materials and Methods}

Cell culture. This study was carried out according to the guidelines of the Instituto de Salud Carlos III (Spain). hMSCs from bone marrow, adipose tissue and articular cartilage were isolated and characterized as previously described. ${ }^{38}$ Human skin fibroblasts were obtained from Inbiobank (San Sebastián, Spain). The $293 \mathrm{~T}$ and the Saos-2 cell lines were purchased from The American Type Culture Collection (CRL-11268, Manasas, VA, USA). All cell lines were maintained in expansion medium, consisting of Dulbecco's modified Eagle's medium supplemented with $1 \mathrm{~g} / \mathrm{I} \mathrm{D}$-glucose, supplemented with $10 \%$ heat-inactivated fetal calf serum (FCS), $2 \mathrm{mM} \mathrm{L-glutamine} \mathrm{and} 50 \mu \mathrm{g} / \mathrm{ml}$ gentamicin; all culture reagents were from Invitrogen (Carlsbad, CA, USA). Cells were cultured in a humidified $37^{\circ} \mathrm{C}$ incubator at $5 \% \mathrm{CO}_{2}$.
For Wnt stimulation, cells were exposed to different concentrations of conditioned medium from Wnt3a-expressing QT6 cells. Control and Wnt3a-expressing QT6 cells were kindly provided by Dr. D Büscher (Cellerix SL, Madrid, Spain).

When indicated, several factors (DKK1, R\&D Systems, Minneapolis, MN, USA; IFN $\gamma$, PeproTech, Rocky Hill, NJ, USA) or chemicals (KCl/LiCl, Sigma-Aldrich, St. Louis, MO, USA) were added to the hMSCs cells to evaluate its effect both on the modulation of miR-335 expression or on the several properties of the cells. In each case, the range of concentrations used is indicated.

Lentiviral vectors. The lentiviral vectors pLV-EmGFP-MIR335 (encoding the human miR-335 gene) and pLV-EmGFP-Mock (encoding a non-specific shRNA sequence) were based on pRRLsin18.PPT.CMV.GFP.Wpre, kindly provided by Dr. Luigi Naldini. ${ }^{39}$ Detailed construction procedures for both plasmids are provided in Supplementary Information.

Lentiviral particles were produced by transient transfection of 293T cells. ${ }^{39}$ Lentiviral transduction was carried out by overnight incubation of $3 \times 10^{5} \mathrm{hMSC}$ in $10 \mathrm{~cm}$ plates with $3 \mathrm{ml}$ culture medium containing lentiviral particles at a $\mathrm{MOI}=5$. Transduced $(\mathrm{gfp}+$ ) cells were purified $48 \mathrm{~h}$ after transduction by FACS using a FACSAriall SORP cell sorter (BD Biosciences, Franklin Lakes, NJ, USA).

Transfection of miRNA precursors and inhibitors. Anti-miR miRNA inhibitors (Ambion) are chemically modified, single-stranded nucleic acids designed to specifically bind and inhibit endogenous miRNAs. Pre-miR miRNA precursors (Ambion) are synthetic double-stranded oligoribonucleotides designed to match the sequence of specific miRNA:miRNA* duplexes. Depending on the experiment, Anti$\mathrm{miR}$ or Pre-miR oligos at a final concentration of $50 \mathrm{nM}$ were transfected (Lipofectamine 2000, Invitrogen) into $2 \times 10^{4} \mathrm{hMSCs}$ cultured in 24-well plates (BD Biosciences) according to the oligonucleotide manufacturer's protocol.

Real-time RT-PCR. Total RNA was isolated from cultured cells with an miRNeasy Mini Kit (Qiagen, Valencia, CA, USA). Human miR-335, MEST, SPP1 (osteopontin), PPARG and RUNX2 transcripts were quantified by real-time RT-PCR using the corresponding TaqMan Gene Expression Assays (Applied Biosystems, Foster City, CA, USA). RNU48 and GAPDH were used as endogenous normalization controls for miRNAs and protein-coding genes, respectively.

Analysis of cell proliferation, cell cycle and apoptosis. Cell proliferation was assessed by seeding $6 \times 10^{4} \mathrm{cells} / 2 \mathrm{ml} / \mathrm{well}$ in six-well plates (Corning, Lowell, MA, USA) and culturing for 30 days. The medium was replaced every $3-4$ days, and the cells were harvested and counted once a week. Cumulative population doubling (CPD) was calculated as $\log _{10}$ (number of cells harvested)$\log _{10}$ (number of cells seeded) $/ \log _{10}{ }^{2}$

For cell cycle profiling, $\sim 1 \times 10^{6}$ methanol:acetic acid-fixed cells were incubated with $10 \mu \mathrm{M}$ propidium iodide and $10 \mu \mathrm{M}$ RNase $\mathrm{A}$ for $1 \mathrm{~h}$ at $37^{\circ} \mathrm{C}$ and analyzed by flow cytometry using a Becton-Dickinson LSR cytometer. Data were analyzed with the Summit v4.3 software (Dako Inc., Carpinteria, CA, USA).

For apoptosis analysis, cells were harvested and centrifuged at $2000 \times g$ for $5 \mathrm{~min}$ at room temperature, washed twice with PBS, and resuspended in $1 \times$ binding buffer (10 mM HEPES/NaOH, pH 7.4, $140 \mathrm{mM} \mathrm{NaCl}, 2.5 \mathrm{mM} \mathrm{CaCl}_{2}$ ) at a concentration of $1 \times 10^{6} \mathrm{cells} / \mathrm{ml}$. A measure of $5 \mu \mathrm{l}$ of Annexin V-DY634 
(Immunostep, Salamanca, Spain) were added to $4 \times 10^{5}$ cells suspended in $400 \mu \mathrm{l}$ of binding buffer. As a negative control, $2 \times 10^{5}$ cells were used without addition of Annexin V antibody. Cells were vortexed gently and incubated in the dark for $15 \mathrm{~min}$ at room temperature. Cells were centrifuged at $1000 \times g$ for $5 \mathrm{~min}$, and $1 \times$ binding buffer $(500 \mu \mathrm{l})$ and $\mathrm{PI}(5 \mu \mathrm{l})$ were added to each tube. The samples were analyzed by FACScan (BD Biosciences) using the Cell Quest software (BD Biosciences).

Cell differentiation assays. hMSCs were seeded at $2 \times 10^{4} \mathrm{cells} / \mathrm{cm}^{2}$ in expansion medium, and after $24 \mathrm{~h}$, medium was replaced by the corresponding induction medium. Osteogenic medium contained expansion medium supplemented with $10 \mathrm{mM} \beta$-glycerophosphate, $0.1 \mu \mathrm{M}$ dexamethasone and $0.2 \mathrm{mM}$ ascorbic acid. Adipogenic medium contained expansion medium supplemented with $0.01 \mu \mathrm{M}$ dexamethasone, $0.5 \mathrm{mM}$ IBMX (3-isobutyl-1-methyl xanthine) and $60 \mu \mathrm{M}$ indomethacin. In all cases, induction medium was replaced every 3-4 days and, on day 9 or 21 (depending on the experiment) cells were processed for histochemical analysis. Cells were fixed with $70 \%$ ethanol $\left(1 \mathrm{~h}, 4^{\circ} \mathrm{C}\right)$ and stained ( $5 \mathrm{~min})$. For osteogenic assays, cells were stained with $40 \mathrm{mM}$ Alizarin Red, $\mathrm{pH}$ 4.1. Cells cultured in adipogenic medium were stained with $2 \%$ Oil Red 0. Analysis of the expression of marker genes for osteogenic (osteopontin) and adipogenic (PPAR $\gamma$ ) differentiation was performed by real-time RT-PCR as described above.

Cell migration assays. For transwell migration assays, hMSCs $\left(1 \times 10^{4}\right)$ were cultured in medium containing $0.2 \%$ FCS in a 24 -well tissue culture insert with an $8-\mu \mathrm{m}$ pore size membrane (BD Biosciences). Fresh culture medium containing $10 \%$ FCS was added to the bottom well. After $6 \mathrm{~h}$, the filter membranes were fixed with $70 \%$ ethanol and mounted in mounting medium containing DAPI. Migration of hMSCs was determined by counting the number of DAPI-stained nuclei on the underside of the membrane under $\times 100$ magnification, using CellProfiler image analysis software (http://www.cellprofiler.org).

For wound-healing assays, a 'wound' was created in a cell monolayer by scraping with a sterile plastic tip, and time-lapse video recordings were made by sequentially capturing microscopic images at $30 \mathrm{~min}$ intervals over a total period of $46 \mathrm{~h}$.

Western blot analysis. Whole-cell lysates for western blotting were extracted with lysis buffer containing $50 \mathrm{mM}$ Tris (pH 8), $150 \mathrm{mM} \mathrm{NaCl}, 1 \mathrm{mM}$ EDTA, $0.1 \%$ Triton $\mathrm{X}-100$ and $0.25 \%$ sodium deoxycholate and protease inhibitor cocktail (Roche, Rotkreuz, Switzerland). Protein samples were resolved by 10\% SDS-PAGE and gels transferred to nitrocellulose membranes (GE Healthcare, Little Chalfont, UK). Membranes were blocked with $5 \%$ non-fat milk for $1 \mathrm{~h}$ at room temperature and subsequently incubated overnight at $4^{\circ} \mathrm{C}$ with primary antibodies at the following dilutions: RUNX2, 1:500 (Sigma-Aldrich) and $\beta$-actin, 1:5000 (AbCam, Cambridge, MA, USA). Signals were detected using the appropriate horseradish peroxidase-conjugated secondary antibody (Dako, Glostrup, Denmark). The blots were visualized by an enhanced chemiluminescence system (ECL; GE Healthcare) according to the manufacturer's instructions, and relative intensity of the specific bands were quantified by densitometry using the ImageJ software (http:// rsb.info.nih.gov/ij/)

UTR reporter assays. The full-length $3^{\prime} U T R$ s of the putative miR-335 target gene RUNX2, as well as the negative control UBE2F and the positive control SOX4 genes were amplified from human genomic DNA (Novagen, Madison, WI, USA) and individually cloned into the Psicheck-2 dual luciferase reporter vector (Promega, Madison, WI, USA). hMSCs were then co-transfected with each reporter construct and with an miRNA synthetic precursor (Pre-miR-335 or Pre-miR negative control \#2, Ambion) or antagonist (Anti-miR-335 or at Anti-miR negative control \#1, Ambion) at a final concentration of $50 \mathrm{nM}$, as described above. Cells were lysed $30 \mathrm{~h}$ after transfection and the ratio of Renilla to firefly luciferase was measured with the dual luciferase assay (Promega). Normalized Renilla to firefly ratios were determined in the presence or absence of miR-335 inhibition.

Microarray analyses. The Agilent Human microRNA Microarray v2.0 (G4470B, Agilent Technologies) was used to identify miRNAs highly expressed in undifferentiated hMSCs. miRNA expression profiles of undifferentiated hMSCs were compared with profiles of human skin fibroblasts and of the same hMSC lines after 9 days of adipogenic or osteogenic induction.

The Agilent Whole Human Genome Microarray Kit (G4112F, Agilent Technologies, Santa Clara, CA, USA) was used to identify genes downregulated in hMSCs exogenously overexpressing miR-335. The mRNA expression profile of hMSCs transduced with lentiviral vector pLV-EmGFP-MIR335 was compared with that of hMSCs transduced with the control vector pLV-EmGFP-Mock.

A full description of the experimental procedures, data processing and statistical analysis used for both types of microarrays is included in Supplementary information. All microarrays have been submitted to the Gene Expression Omnibus database at http://www.ncbi.nlm.nih.gov/geo; accession number GSE19232.

Bioinformatic analysis. Computational miRNA target prediction analyses were carried out using the algorithms miRanda (http://www.microrna.org/microrna/ home.do), TargetScan (http://www.targetscan.org) and PicTar (http://pictar. mdc-berlin.de).

Human, mouse and dog MEST loci were aligned, and the extent of DNA sequence homology was computed with the web-based program MULAN (http:// mulan.dcode.org)..$^{40}$ Using MULAN and multiTF (http://multitf.dcode.org) with the TRANSFAC professional V10.2 library database (http://www.biobase.de), binding sites for LEF1, TCF4 (0.95 matrix similarity) and STAT1 ( 0.9 matrix similarity) were predicted in the $5-\mathrm{kb}$ upstream region of the human MEST locus.

Target gene functions were profiled with PANTHER software (http:// www.pantherdb.org/tools) and Ingenuity Pathways Analysis software (http:// www.ingenuity.com).

Statistical analysis. Statistical analyses of experimental data were conducted with Prism 3.0 (Graphpad Software Inc., San Diego, CA, USA). Unless otherwise stated, data were compared by the Mann-Whitney $U$-test for statistical significance. Results were considered statistically significant at $P \leq 0.05$.

\section{Conflict of interest}

The authors declare no conflict of interest.

Acknowledgements. We thank S Calleja and R Alvarez (CNIC) for technical help with microarrays and real-time RT-PCR; P Fernández and JC Ramírez (CNIC) for lentivirus production; $\mathrm{F}$ Cabo $(\mathrm{CNIC})$ for bioinformatics and statistical support; C Carreiro and A Esteban (CNIC) for preparation and maintenance of plasmid stocks; M García-Arranz (Hospital Univesitario La Paz, Madrid, Spain), C Trigueros, A Izeta and A García (F Inbiomed, San Sebastián, Spain) for biological samples; $S$ Bartlett (CNIC) for English revision and M Ramón for secretarial support. This work was supported by grants to $A B$ from the Spanish Plan Nacional de Salud y Farmacia/CICYT (SAF 2008-02099), Comunidad Autónoma de Madrid (P-BIO-0306-2006) and Red de Terapia Celular del Instituto de Salud Carlos III (TerCel); MAG is supported by the 'Miguel Servet' Program (CP07/00306) of the Instituto de Salud Carlos III (Ministerio de Ciencia e Innovación, Spain); JCS is supported by the ACI-PLAN-E Program (Ministerio de Ciencia e Innovación, Spain). The CNIC is supported by the Spanish Ministry of Science and Innovation and the Pro-CNIC Foundation.

1. Bernardo ME, Locatelli F, Fibbe WE. Mesenchymal stromal cells. Ann N Y Acad Sci2009; 1176: 101-117.

2. Berezikov E, Guryev V, van de Belt J, Wienholds E, Plasterk RH, Cuppen E. Phylogenetic shadowing and computational identification of human microRNA genes. Cell 2005; 120: 21-24.

3. Hwang HW, Wentzel EA, Mendell JT. A hexanucleotide element directs microRNA nuclear import. Science 2007; 315: 97-100.

4. Valadi H, Ekstrom K, Bossios A, Sjostrand M, Lee JJ, Lotvall JO. Exosome-mediated transfer of mRNAs and microRNAs is a novel mechanism of genetic exchange between cells. Nat Cell Biol 2007; 9: 654-659.

5. Kanellopoulou C, Muljo SA, Kung AL, Ganesan S, Drapkin R, Jenuwein T et al. Dicerdeficient mouse embryonic stem cells are defective in differentiation and centromeric silencing. Genes Dev 2005; 19: 489-501.

6. Wang $\mathrm{Y}$, Medvid R, Melton C, Jaenisch R, Blelloch R. DGCR8 is essential for microRNA biogenesis and silencing of embryonic stem cell self-renewal. Nat Genet 2007; 39: $380-385$.

7. Suh MR, Lee Y, Kim JY, Kim SK, Moon SH, Lee JY et al. Human embryonic stem cells express a unique set of microRNAs. Dev Biol 2004; 270: 488-498.

8. Tay Y, Zhang J, Thomson AM, Lim B, Rigoutsos I. MicroRNAs to Nanog, Oct4 and Sox2 coding regions modulate embryonic stem cell differentiation. Nature 2008; 455 : $1124-1128$. 
9. Mizuno Y, Yagi K, Tokuzawa Y, Kanesaki-Yatsuka Y, Suda T, Katagiri T et al. miR-125b inhibits osteoblastic differentiation by down-regulation of cell proliferation. Biochem Biophys Res Commun 2008; 368: 267-272.

10. Luzi E, Marini F, Sala SC, Tognarini I, Galli G, Brandi ML. Osteogenic differentiation of human adipose tissue-derived stem cells is modulated by the miR-26a targeting of the SMAD1 transcription factor. J Bone Miner Res 2008; 23: 287-295.

11. Kim YJ, Bae SW, Yu SS, Bae YC, Jung JS. miR-196a regulates proliferation and osteogenic differentiation in mesenchymal stem cells derived from human adipose tissue. J Bone Miner Res 2009; 24: 816-825.

12. Huang J, Zhao L, Xing L, Chen D. MicroRNA-204 regulates Runx2 protein expression and mesenchymal progenitor cell differentiation. Stem Cells 2010; 28: 357-364.

13. Schoolmeesters A, Eklund T, Leake D, Vermeulen A, Smith Q, Force Aldred S et al. Functional profiling reveals critical role for miRNA in differentiation of human mesenchymal stem cells. PLoS One 2009; 4: e5605.

14. Bae S, Ahn JH, Park CW, Son HK, Kim KS, Lim NK et al. Gene and microRNA expression signatures of human mesenchymal stromal cells in comparison to fibroblasts. Cell Tissue Res 2009; 335: 565-573.

15. Lopez-Romero P, Gonzalez MA, Callejas S, Dopazo A, Irizarry RA. Processing of Agilent microRNA array data. BMC Res Notes 2010; 3: 18

16. Kobayashi S, Kohda T, Miyoshi N, Kuroiwa Y, Aisaka K, Tsutsumi O et al. Human PEG1/ MEST, an imprinted gene on chromosome 7. Hum Mol Genet 1997; 6: 781-786.

17. Boland GM, Perkins G, Hall DJ, Tuan RS. Wnt 3a promotes proliferation and suppresses osteogenic differentiation of adult human mesenchymal stem cells. J Cell Biochem 2004; 93: $1210-1230$.

18. Krampera M, Cosmi L, Angeli R, Pasini A, Liotta F, Andreini A et al. Role for interferongamma in the immunomodulatory activity of human bone marrow mesenchymal stem cells. Stem Cells 2006; 24: 386-398.

19. Duque G, Huang DC, Macoritto M, Rivas D, Yang XF, Ste-Marie LG et al. Autocrine regulation of interferon gamma in mesenchymal stem cells plays a role in early osteoblastogenesis. Stem Cells 2009; 27: 550-558.

20. Enright AJ, John B, Gaul U, Tuschl T, Sander C, Marks DS. MicroRNA targets in Drosophila. Genome Biol 2003; 5: R1.

21. Lewis BP, Burge CB, Bartel DP. Conserved seed pairing, often flanked by adenosines, indicates that thousands of human genes are microRNA targets. Cell 2005; 120: 15-20.

22. Krek A, Grun D, Poy MN, Wolf R, Rosenberg L, Epstein EJ et al. Combinatorial microRNA target predictions. Nat Genet 2005; 37: 495-500.

23. Sood P, Krek A, Zavolan M, Macino G, Rajewsky N. Cell-type-specific signatures of microRNAs on target mRNA expression. Proc Natl Acad Sci USA 2006; 103: 2746-2751.

24. Tavazoie SF, Alarcon C, Oskarsson T, Padua D, Wang Q, Bos PD et al. Endogenous human microRNAs that suppress breast cancer metastasis. Nature 2008; 451: 147-152.

25. Andl T, Murchison EP, Liu F, Zhang Y, Yunta-Gonzalez M, Tobias JW et al. The miRNAprocessing enzyme dicer is essential for the morphogenesis and maintenance of hair follicles. Curr Biol 2006; 16: 1041-1049.
26. Sorrentino A, Liu CG, Addario A, Peschle C, Scambia G, Ferlini C. Role of microRNAs in drug-resistant ovarian cancer cells. Gynecol Oncol 2008; 111: 478-486.

27. Dunn W, DuRaine G, Reddi AH. Profiling microRNA expression in bovine articular cartilage and implications for mechanotransduction. Arthritis Rheum 2009; 60: 2333-2339.

28. Sathyan P, Golden HB, Miranda RC. Competing interactions between micro-RNAs determine neural progenitor survival and proliferation after ethanol exposure: evidence from an ex vivo model of the fetal cerebral cortical neuroepithelium. J Neurosci 2007; 27: $8546-8557$

29. Ronchetti D, Lionetti M, Mosca L, Agnelli L, Andronache A, Fabris S et al. An integrative genomic approach reveals coordinated expression of intronic miR-335, miR342 , and miR-561 with deregulated host genes in multiple myeloma. BMC Med Genomics 2008; $1: 37$

30. Greco SJ, Rameshwar P. MicroRNAs regulate synthesis of the neurotransmitter substance $\mathrm{P}$ in human mesenchymal stem cell-derived neuronal cells. Proc Natl Acad Sci USA 2007; 104: $15484-15489$

31. Nakanishi N, Nakagawa Y, Tokushige N, Aoki N, Matsuzaka T, Ishii K et al. The upregulation of microRNA-335 is associated with lipid metabolism in liver and white adipose tissue of genetically obese mice. Biochem Biophys Res Commun 2009; 385: 492-496.

32. Williams AE, Moschos SA, Perry MM, Barnes PJ, Lindsay MA. Maternally imprinted microRNAs are differentially expressed during mouse and human lung development. Dev Dyn 2007; 236: 572-580.

33. Scarola M, Schoeftner S, Schneider C, Benetti R. miR-335 directly targets Rb1 (pRb/p105) in a proximal connection to p53-dependent stress response. Cancer Res Sep 1; 70: 6925-6933.

34. Ge W, He F, Kim KJ, Blanchi B, Coskun V, Nguyen L et al. Coupling of cell migration with neurogenesis by proneural bHLH factors. Proc Natl Acad Sci USA 2006; 103: 1319-1324.

35. Neth $\mathrm{P}$, Ciccarella M, Egea V, Hoelters J, Jochum M, Ries C. Wnt signaling regulates the invasion capacity of human mesenchymal stem cells. Stem Cells 2006; 24: 1892-1903.

36. Karow M, Popp T, Egea V, Ries C, Jochum M, Neth P. Wnt signalling in mouse mesenchymal stem cells: impact on proliferation, invasion and MMP expression. J Cell Mol Med 2009; 13 (8B): 2506-2520

37. Fillmore RA, Mitra A, Xi Y, Ju J, Scammell J, Shevde LA et al. Nmi (N-Myc interactor) inhibits Wnt/beta-catenin signaling and retards tumor growth. Int J Cancer 2009; 125: 556-564.

38. de la Fuente R, Abad JL, Garcia-Castro J, Fernandez-Miguel G, Petriz J, Rubio D et al. Dedifferentiated adult articular chondrocytes: a population of human multipotent primitive cells. Exp Cell Res 2004; 297: 313-328.

39. Zufferey R, Dull T, Mandel RJ, Bukovsky A, Quiroz D, Naldini L et al. Self-inactivating lentivirus vector for safe and efficient in vivo gene delivery. J Virol 1998; 72: 9873-9880.

40. Ovcharenko I, Loots GG, Giardine BM, Hou M, Ma J, Hardison RC et al. Mulan: multiplesequence local alignment and visualization for studying function and evolution. Genome Res 2005; 15: 184-194.

\section{Supplementary Information accompanies the paper on Cell Death and Differentiation website (http://www.nature.com/cdd)}

